\title{
Pierre Corneille, Cinna
}

\section{Laura Rescia}

\section{OpenEdition}

\section{Journals}

\section{Edizione digitale}

URL: http://journals.openedition.org/studifrancesi/3717

DOI: 10.4000/studifrancesi.3717

ISSN: 2421-5856

\section{Editore}

Rosenberg \& Sellier

\section{Edizione cartacea}

Data di pubblicazione: 1 décembre 2012

Paginazione: $561-562$

ISSN: 0039-2944

\section{Notizia bibliografica digitale}

Laura Rescia, «Pierre Corneille, Cinna», Studi Francesi [Online], 168 (LVI | III) | 2012, online dal 30

novembre 2015, consultato il 08 mars 2021. URL: http://journals.openedition.org/studifrancesi/3717 ; DOI: https://doi.org/10.4000/studifrancesi.3717

Questo documento è stato generato automaticamente il 8 mars 2021.

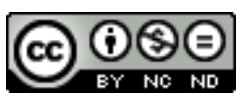

Studi Francesi è distribuita con Licenza Creative Commons Attribuzione - Non commerciale - Non opere derivate 4.0 Internazionale. 


\title{
Pierre Corneille, Cinna
}

\author{
Laura Rescia
}

\section{NOTIZIA}

PIERRE CORNEILLE, Cinna, éd. critique A. RIFFAUD, Genève, Droz («Textes Littéraires

Français»), 2011, pp. 248.

1 Le edizioni critiche dell'opera di Pierre Corneille fanno ormai data: il volume della Pléiade curato da Georges Couton risale alla fine degli anni Settanta, e, in attesa che Garnier dia alle stampe la nuova edizione dell'opera omnia sotto la direzione di Liliane Picciola, segnaliamo questo lavoro, che, per quanto isolato, presenta alcuni aspetti di un certo interesse. Nella più classica delle tradizioni filologiche, l'A. sceglie di seguire l'edizione del 1682, notoriamente l'ultima rivista da Corneille, e ne offre una versione modernizzata. Tuttavia, una scelta particolare riguarda la punteggiatura e le maiuscole, cosa che non stupirà chi conosce l'interesse dello studioso per i fenomeni interpuntivi, ma che può risultare curiosa: si opta per la riproduzione fedele dell'edizione in-folio del 1663, motivando tale scelta con l'impossibilità di ricostruire, per questo aspetto del testo, la volontà dell'autore, attribuendo le scelte di punteggiatura interamente alle pratiche tipografiche. Non si persegue dunque la strada della punteggiatura e maiuscolatura declamatoria, ma si propende per la ricostruzione della maggiore attendibilità di una punteggiatura sintattica: e in tal senso l'edizione del 1663 appare senz'altro come la più curata e maggiormente attendibile. La crasi tra la modernizzazione del testo e un'attenzione massimamente filologica alla punteggiatura antica fa sorgere qualche interrogativo: tuttavia, ne risulta un testo di buona leggibilità. La sua collocazione editoriale lo destina principalmente agli studiosi: ma gli apparati e le appendici (in particolare il dossier critico finale) che lo accompagnano hanno un certo sapore didattico, che rivela dunque una doppia intenzione editoriale e una doppia possibilità di utilizzo.

2 La ricca introduzione è largamente debitrice a Forestier e al suo concetto di génétique théâtrale: tuttavia, l'esegesi di Riffaud dà grande rilevanza al tema politico corneliano, 
inquadrando il testo con ricchezza di riferimenti filosofici (e qualche estratto comparativo è altresì contenuto nel dossier) e alle fonti classiche. Ne emerge pertanto una visione di Corneille drammaturgo conciliabile con la visione del Corneille teorico politico. Lo studioso rivela altresì il suo interesse per il mondo contemporaneo, con un ardito tentativo di attualizzazione delle tematiche corneliane, alla luce della globalizzazione e dei problemi legati alla legittimità del potere politico.

Il procedimento critico rigoroso, e la gran messe di edizioni ed esemplari consultati danno conto della serietà di quest'edizione: ci si rammarica che la collocazione delle varianti in fondo al testo, certamente imposta dall'editore, sminuisca quest'aspetto del lavoro critico, sottraendolo sistematicamente all'attenzione del lettore meno filologicamente sensibile. Sintetica la bibliografia finale, che restituisce nella sua eterogeneità la lettura del suo curatore. 